Provided for non-commercial research and education use. Not for reproduction, distribution or commercial use.

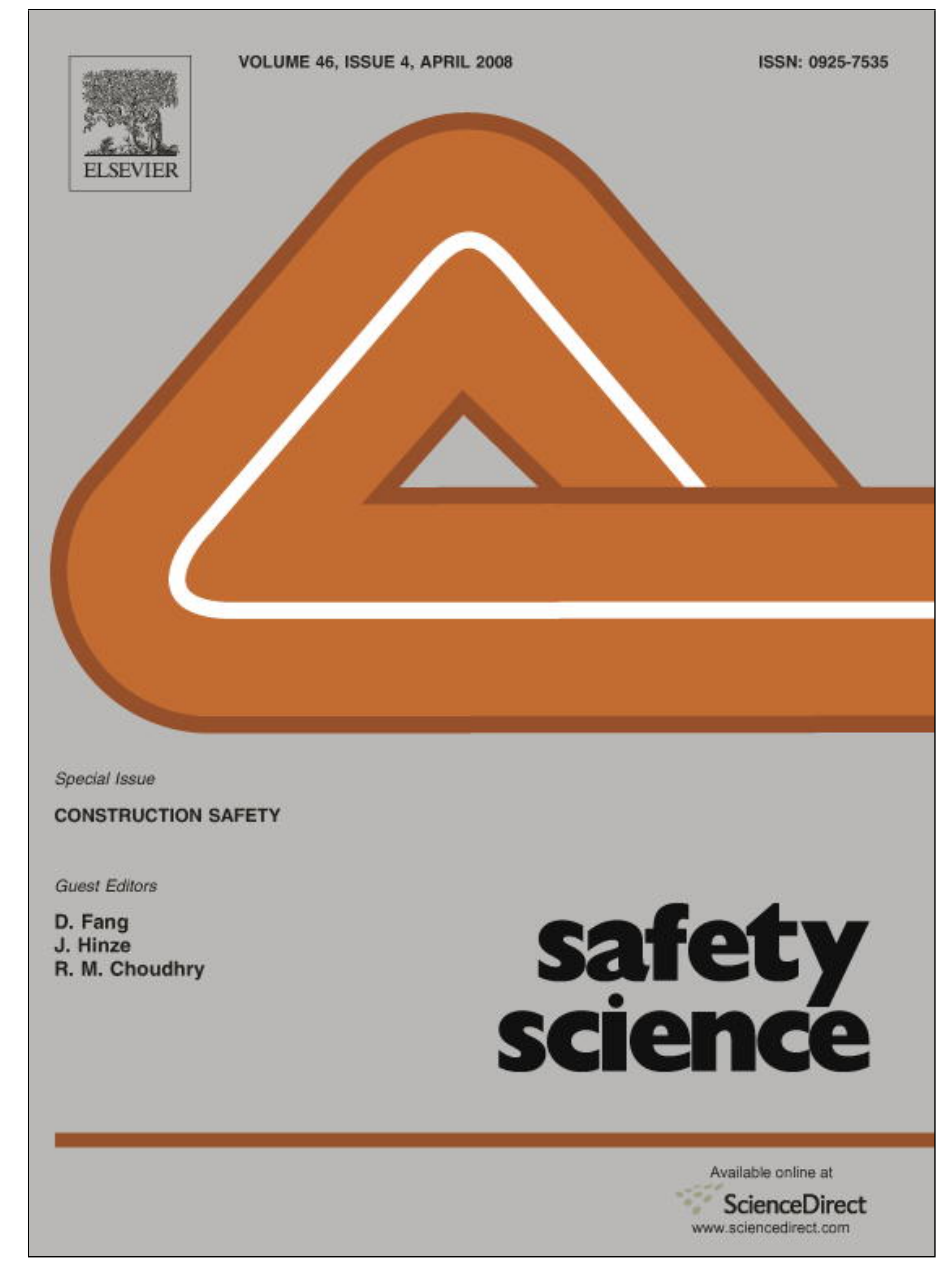

This article appeared in a journal published by Elsevier. The attached copy is furnished to the author for internal non-commercial research and education use, including for instruction at the authors institution and sharing with colleagues.

Other uses, including reproduction and distribution, or selling or licensing copies, or posting to personal, institutional or third party websites are prohibited.

In most cases authors are permitted to post their version of the article (e.g. in Word or Tex form) to their personal website or institutional repository. Authors requiring further information regarding Elsevier's archiving and manuscript policies are encouraged to visit:

http://www.elsevier.com/copyright 


\title{
Comparison of characteristics between fatal and injury accidents in the highway construction zones
}

\author{
Yingfeng $\mathrm{Li}^{\mathrm{a}, *}$, Yong Bai ${ }^{\mathrm{b}, 1}$ \\ a Department of Civil, Environmental and Architectural Engineering, 1530 West 15th Street, \\ 2160 Learned Hall, The University of Kansas, Lawrence, KS 66045-7609, USA \\ ${ }^{\mathrm{b}}$ Department of Civil, Environmental and Architectural Engineering, 1530 West 15th Street, \\ 2150 Learned Hall, The University of Kansas, Lawrence, KS 66045-7609, USA
}

\begin{abstract}
Highway construction zone safety has been a research focus in many countries for many decades. In the United States, regardless of the research efforts devoted, highway construction zones remain a serious safety concern for government agencies, legislatures, the highway industry, and the traveling public. In this study, the fatal and injury accidents between 1992 and 2004 in Kansas highway construction zones were examined systematically and their major characteristics were compared. The results showed significant differences between fatal and injury accidents in the construction zones. The researchers found that: (1) head-on was the dominant type for fatal accidents while rear-end was the dominant injury accident type; (2) a large percent of fatal accidents involved trucks while a majority of injury accidents involved light-duty vehicles only; (3) disregarded traffic control, alcohol impairment, and speeding caused a much larger proportion of fatal accidents while followed too close caused a much higher percentage of injury accidents; and (4) unfavorable light conditions and complicated road geometries contributed to causing a larger percentage of fatal accidents than to causing injury accidents. Based on the study results, practical safety countermeasures targeted at different severity of accidents are recommended in terms of construction zone traffic control and public education.
\end{abstract}

(c) 2007 Elsevier Ltd. All rights reserved.

Keywords: Accident; Construction zone; Highway; Characteristics; Safety

\footnotetext{
* Corresponding author. Tel.: +1 785864 2598; fax: +1 7858645631.

E-mail addresses: Lyf537@ku.edu (Y. Li), ybai@ku.edu (Y. Bai).

${ }^{1}$ Tel.: +1 785864 2991; fax: +1 7858645631 .
} 


\section{Introduction}

The continuously increasing number of highway construction zones has created an inevitable disruption of regular traffic flows and has resulted in traffic safety problems in many countries. In the United States, many efforts have been devoted to improving the safety and mobility for construction zone traffic. Highway construction zone safety was emphasized by the US legislature in the recent safe, accountable, flexible, efficient transportation equity act: a legacy for users (SAFETEA-LU). Other concerned organizations and researchers have launched a campaign to improve the safety by conducting practical research on various construction zone safety-related issues. A significant number of relevant studies have been published to unveil the safety problems and to propose safety improvements in construction zones (Bai and Cao, 2003).

Regardless of these efforts, highway construction zone safety remains unsatisfactory (Bai, 2002). Although accident rates by vehicle miles traveled (VMT) in construction zones are not precisely known, statistics have shown serious traffic safety concerns. In the United States, annual construction zone fatalities rose from 872 in 1999 to 1028 in 2003 (an average of 1020 per year during this period), adding another 40,000 construction zone related injuries per year (FHWA, 2004). The estimated direct costs of highway construction zone accidents were as high as $\$ 6.2$ billion per year between 1995 and 1997 with an average cost of $\$ 3687$ per accident (Mohan and Gautam, 2002). The alarming numbers indicate an urgent need for improving construction zone safety.

Studying the characteristics of accidents in the construction zones is the first step towards the identification of construction zone safety deficiencies and potential countermeasures. In addition, investigating the characteristic differences between accidents of different severities (fatal vs. injury) may lead to the discovery of factors causing severity increase, which may benefit the development of traffic controls for reducing the proportion of high-severity crashes in total accidents. This paper presents the results of a characteristic-comparison study between fatal and injury accidents in the construction zones. This comparison study provides significant insights for developing effective traffic control strategies that could reduce the number of construction zone accidents and mitigate the severity of accidents.

\section{Literature review}

At the beginning of this research, a comprehensive literature review was conducted to synthesize the findings of previous studies on construction zone accident characteristics. The predominant construction zone accident characteristics from the previous studies are summarized in terms of severity, rate, type, time, location, and causal factors.

\subsection{Accident severity}

Studies have reached inconsistent conclusions about whether more severe accidents occur in construction zones than other highway sections. Some studies from Virginia (Garber and Zhao, 2002), Texas (Ullman and Krammes, 1990), Kentucky (Pigman and Agent, 1990), and Ohio (Nemeth and Migletz, 1978) documented significant increases in severe accidents in construction zones. A national study (AASHTO, 1987) also discovered that both fatal accident frequency and average fatalities per accident were higher 
in construction zones across the nation. However, several other studies (Chambless et al., 2002; Ha and Nemeth, 1995; Hall and Lorenz, 1989) did not find significant changes on construction zone accident severity. The construction zone accidents were even found to be less severe in a few other studies (Wang et al., 1996; Garber and Woo, 1990; Rouphail et al., 1988; Hargroves, 1981).

\subsection{Accident rate}

Since highway construction zones disrupt regular traffic flows, higher accident rates would be an anticipated outcome. Many studies (Garber and Zhao, 2002; Pigman and Agent, 1990; AASHTO, 1987; Hall and Lorenz, 1989; Pal and Sinha, 1996; Graham et al., 1977) showed higher accident rates in highway construction zones. In particular, some studies (Ullman and Krammes, 1990; Rouphail et al., 1988) suggested that considerable accident-rate increases could be expected in long-term highway construction zones.

\subsection{Accident type}

The prevailing types of construction zone accidents vary with different locations and times, but it was agreed by most of the previous studies that rear-end collision was one of the most frequent construction zone accident types (Mohan and Gautam, 2002; Garber and Zhao, 2002; Pigman and Agent, 1990; Nemeth and Migletz, 1978; Chambless et al., 2002; Hall and Lorenz, 1989; Wang et al., 1996; Garber and Woo, 1990; Rouphail et al., 1988; Hargroves, 1981; Sorock et al., 1996). Other major accident types in construction zones include same-direction sideswipe collision (Pigman and Agent, 1990; Garber and Woo, 1990) and angle collision (Pigman and Agent, 1990). Some studies ranked hit-fixed-object as another dominant type of construction zone accident (Mohan and Gautam, 2002; Nemeth and Migletz, 1978; Hargroves, 1981). A study in Georgia found that single-vehicle accidents, angle, and head-on collisions were the dominant types of fatal construction zone accidents (Daniel et al., 2000).

Another major safety concern is the frequent involvement of heavy trucks in construction zone accidents. Several studies found that the percentage of truck-involved accidents was much higher in construction zones (Pigman and Agent, 1990; AASHTO, 1987) and heavy truck related accidents were more likely to involve multiple vehicles and hence frequently resulted in fatalities and large monetary loss (Bai and Li, 2006; Pigman and Agent, 1990; Schrock et al., 2004; Hill, 2003). Benekohal et al. (1995) found in a survey that $90 \%$ of the truck drivers considered that driving through construction zones was more hazardous than driving through other areas.

\subsection{Accident time}

Construction zone accidents frequently occur in the daytime during the busiest construction season between June and October (Mohan and Gautam, 2002; Chambless et al., 2002; Hill, 2003; Li and Bai, 2006; Pigman and Agent, 1990). Nighttime construction zone accidents, however, were found to be much more severe in most cases (Garber and Zhao, 2002; Pigman and Agent, 1990; AASHTO, 1987). Nemeth and Migletz (1978) found that the proportion of tractor-trailer- or bus-caused accidents at darkness was greater 
than the proportion of other vehicles, which consequently resulted in more severe accidents due to the large sizes of tractor-trailers and buses.

\subsection{Accident location}

A national study found that the construction zones on rural highways accounted for $69 \%$ of all fatal accidents (AASHTO, 1987). In particular, the rural interstate systems or two-lane highways were the places where construction zone accidents were most likely to occur (Pigman and Agent, 1990; AASHTO, 1987; Chambless et al., 2002; Rouphail et al., 1988). However, a Virginia study (Garber and Zhao, 2002) argued that, in general, urban highways had much higher percentage of construction zone accidents than rural highways.

\subsection{Causal factors}

Many previous studies pointed at human errors, such as following too close, inattentive driving, and misjudging, as the primary causes for construction zone accidents (Mohan and Gautam, 2002; Pigman and Agent, 1990; Chambless et al., 2002; Hargroves, 1981; Daniel et al., 2000). Some studies also indicated that speeding (Garber and Zhao, 2002) and inefficient traffic control (Ha and Nemeth, 1995) were two other factors causing accidents in construction zones. Hill (2003) found that there was a significant difference on types of driver errors between daytime accidents and nighttime accidents. Researchers found that adverse environmental and road surface conditions did not contribute more to construction zone accidents than to accidents at other places (Nemeth and Migletz, 1978; Garber and Woo, 1990).

In summary, construction zone accidents have been a research focus for decades and some of the earliest research results were published in 1960s. To date, most construction zone accident studies have been conducted statewide and their findings vary with data sources. The researchers did not find any studies that compared the characteristics of fatal and injury accidents in construction zones. This type of comparison could provide new knowledge to develop effective traffic control strategies that can be used not only to reduce the number of construction zone accidents but also to mitigate the severity of accidents.

\section{Objectives, scope, and methodology}

The primary objectives of this research are: (1) to investigate the characteristics of fatal and injury accidents in highway construction zones, (2) to determine if there is a difference between fatal and injury accident through characteristic comparison, and (3) to recommend safety countermeasures considering the different characteristics between fatal and injury accidents.

The scope of this research is limited to the fatal and injury accidents between 1992 and 2004 in Kansas highway construction zones. The research objectives were achieved in four steps. First, a comprehensive literature review was conducted and results were presented in the previous chapter. Second, the data of fatal and injury accidents was abstracted from accident database developed and managed by the Kansas department of transportation (KDOT). Third, the collected data were analyzed using frequency analysis and chi-square 
statistics and the major characteristics between fatal and injury accidents were compared. Finally, conclusions and recommendations for improvements were outlined.

\section{Data collection and data analysis methods}

\subsection{Data collection}

Data for fatal and injury accidents in Kansas highway construction zones between 1992 and 2004 was collected from a database. The original data from KDOT's accident database had a format where a single accident was frequently described in multiple data rows and accident information was recorded using text. This data format could not be directly utilized for analysis using computer software such as SAS. Thus, accident data had to be compiled into a single row per accident in the spreadsheet without missing key information of interest. During this process, text information was also translated into numerical values. In the study period, Kansas construction zones had 157 fatal accidents and 4443 injury accidents. It would be extremely time-consuming yet not statistically meaningful to compile and analyze the entire fatal and injury accidents. Instead, a total of 157 fatal accidents and a sample of 460 injury accidents were selected to save data collection time while still maintaining the reasonable accuracy of analysis results.

The sample size for injury accidents was determined based on the method introduced by Thompson (2002). Considering that the data would be used for frequency analysis of characteristics reflected through the proportions of the different accidents marked by different variable observations, the sample size was determined such that the proportions could be estimated accurately. Based on normal approximation, to obtain a proportion estimator $\hat{p}$ with a probability of at least $1-\alpha$ of being no farther than $d$ (error) from the true population proportion $p$, one would choose a corresponding sample size such that

$$
P(|\hat{p}-p|>d)<\alpha .
$$

According to Thompson (2002), when there is no estimate of $p$ available and the population size $N$ is large, the following equation can be used to determine the minimum sample size $n_{\min }$ :

$$
n_{\min }=\frac{1}{(N-1) / N n_{0}+1 / N} \approx \frac{1}{1 / n_{0}+1 / N},
$$

where

$$
n_{0}=\frac{z_{\alpha / 2}^{2} p(1-p)}{d^{2}}=\frac{0.25 z_{\alpha / 2}^{2}}{d^{2}}
$$

and $z_{\alpha / 2}$ is the upper $\alpha / 2$ point of the standard normal distribution.

For multi-proportion estimations, Thompson (2002) showed that $n_{0}$ was equal to 510 when $\alpha=d=0.05$ and when the population size $N$ was large. Given the 4443 injury accident population from this study, the minimum sample size needed for frequency analysis at $95 \%$ confidence level (an error $d$ less than 5\%) was determined using the above equation as:

$$
n_{\min } \approx \frac{1}{1 / n_{0}+1 / N}=\frac{1}{1 / 510+1 / 4443}=457
$$

and rounded to 460 . 
The data collection was conducted in two steps. First, based on KDOT's database, drivers at fault were identified and their characteristics were compiled along with other accident information into spreadsheets where an accident was described in one data row. Then, for the cases with missing or unclear information, the original accident reports, including detailed accident descriptions in text and sketches, were examined to ensure the data accuracy. The collected accident information contained six categories. Each category had several accident variables as listed in Table 1. The observations of these accident variables were assigned unique integers so that the spreadsheet contained only numerical data. For instance, 0 and 1 were assigned to the variable of gender to represent male and female, respectively.

\subsection{Data analysis methods}

The fatal and injury accidents in the highway construction zones were first analyzed separately to identify their respective characteristics. Then, the researchers compared the characteristics between fatal and injury accidents. The focus of this paper is to present the characteristic comparison between fatal and injury accidents. For both types of the accident, frequency analysis was utilized to discover the basic characteristics based on singlevariable frequencies and the more complicated characteristics based on cross-categorized

Table 1

Data categories and variables

\begin{tabular}{|c|c|c|}
\hline No. & Category & Variable \\
\hline \multirow[t]{2}{*}{1} & \multirow[t]{2}{*}{ Driver at fault } & Age \\
\hline & & Gender \\
\hline \multirow[t]{4}{*}{2} & \multirow[t]{4}{*}{ Time } & Time \\
\hline & & Day \\
\hline & & Month \\
\hline & & Year \\
\hline \multirow[t]{3}{*}{3} & \multirow[t]{3}{*}{ Accident environment conditions } & Lighting \\
\hline & & Weather \\
\hline & & Road surface \\
\hline \multirow[t]{7}{*}{4} & \multirow[t]{7}{*}{ Road conditions } & Surface type \\
\hline & & Lane number \\
\hline & & Road class \\
\hline & & Speed limit \\
\hline & & Area information \\
\hline & & Road character \\
\hline & & Road special feature \\
\hline \multirow[t]{6}{*}{5} & \multirow[t]{6}{*}{ Accident scene information } & Accident location \\
\hline & & No. of cars in collision \\
\hline & & Vehicle maneuver before accident \\
\hline & & Accident type \\
\hline & & Vehicle type \\
\hline & & Traffic control device \\
\hline \multirow[t]{4}{*}{6} & \multirow[t]{4}{*}{ Other contributing factors } & Driver \\
\hline & & Pedestrian \\
\hline & & Environment \\
\hline & & Vehicle \\
\hline
\end{tabular}


multi-variable frequencies. The variable combinations were identified through statistical independence test methods such as Pearson chi-square test and likelihood-ratio (LR) chi-square test. The former is a more robust test of independence for small samples. On the other hand, the LR chi-square is more appropriate for use in hierarchical models (UT, 2005). Regardless of the different advantages, they were both adopted to avoid missing potential interrelated variable pairs. The theories of these two test methods and detailed applications were presented in Li and Bai (2006).

\section{Comparing characteristics of fatal and injury accidents}

The collected fatal and injury accident data were analyzed and their characteristics were compared. The different characteristics of the two types of accident were determined and similar characteristics were also outlined. These results are valuable for the thorough understanding of the general characteristics of fatal vs. injury accidents as well as the unique characteristics distinguishing different accident severities. The comparison also unveiled some important factors that might contribute to a more severe accident. Note that the comparisons were based on percent frequencies of the accidents because only a sample of 460 injury accidents was analyzed. In addition, comparing on a percentage basis instead of absolute numbers would avoid the important characteristics of fatal accidents being overwhelmed by those of the injury accidents that had the much larger number. Table 2 lists the most frequent observations for both fatal and injury crash variables. The comparison results are presented in terms of driver, time information, climatic environment, accident information, road condition, and contributing factor.

\subsection{Information of drivers at fault}

Male drivers caused the majority of both fatal and injury accidents in Kansas construction zones. Young drivers between 15 and 24 years of age were the driver group frequently involved in the severe accidents. In particular, teenage drivers between 15 and 19 years of age caused $16 \%$ of the construction zone injury accidents, a percentage that was triple of the percentage of this driver group in the total nationwide driver population (FHWA, 2006). Among the injury accidents caused by teenage drivers, male teenagers were responsible for $94 \%$. Frequency analyses based on chi-square tests showed that male drivers also caused a higher proportion of single-vehicle injury accidents than multi-vehicle injury accidents. In addition, 55\% of the light-duty vehicle injury accidents were caused by drivers younger than 35 . The term "light-duty vehicle" refers to the vehicle types including passenger car, van, pickup truck, sport utility vehicle (SUV), all terrain vehicle (ATV), and camper or recreational vehicle (RV). The majority of nighttime accidents were caused by drivers younger than 55 years of age.

Characteristic comparisons showed that the percentage of male drivers responsible for the fatal accidents was higher than that for the injury accidents by $9 \%(75 \% \mathrm{vs}$. $66 \%$ as shown in Table 2). Fig. 1 illustrates the fatal and injury accident distributions over driver age. Drivers younger than 34 years of age caused a higher percentage of injury accidents than fatal accidents. The drivers aged 35-44 caused the highest percentage $(24 \%)$ of the fatal accidents among all the age groups, which was $9 \%$ higher than the injury accidents 
Table 2

Most frequent observations for fatal and injury crash variables

\begin{tabular}{|c|c|c|}
\hline \multirow[t]{2}{*}{ Variable } & \multicolumn{2}{|l|}{ Most frequent observations } \\
\hline & Fatal accident & Injury accident \\
\hline \multicolumn{3}{|c|}{ Information of drivers at fault } \\
\hline Gender & Male $(75 \%)$ & Male $(66 \%)$ \\
\hline Age & $35-44(24 \%)$ & $15-24(33 \%)$ \\
\hline \multicolumn{3}{|l|}{ Accident time information } \\
\hline Time & 8:00 p.m.-6:00 a.m. $(37 \%)$ & 10:00 a.m. $-4: 00$ p.m. $(42 \%)$ \\
\hline Day & Saturday $(17 \%)$ & Friday $(18 \%)$ \\
\hline Month & June $(14 \%)$ & August (15\%) \\
\hline \multicolumn{3}{|c|}{ Climatic environmental information } \\
\hline Light condition & Daylight $(53 \%)$ & Daylight (75\%) \\
\hline Weather condition & Good $(91 \%)$ & Good $(87 \%)$ \\
\hline Road surf. condition & Dry $(88 \%)$ & Dry $(84 \%)$ \\
\hline \multicolumn{3}{|l|}{ Accident information } \\
\hline Vehicle maneuver & Following road $(74 \%)$ & Following road $(68 \%)$ \\
\hline Accident type & Head-on $(24 \%)$ & Rear-end (46\%) \\
\hline Vehicle body type & Truck-vehicle $(34 \%)$ & Vehicle-vehicle $(58 \%)$ \\
\hline No. of vehicles & Two $(53 \%)$ & Two $(50 \%)$ \\
\hline \multicolumn{3}{|l|}{ Road conditions } \\
\hline Road class & Other principle arterials $(56 \%)$ & Other principal arterials $(40 \%)$ \\
\hline Road character & Straight and level $(51 \%)$ & Straight and level $(66 \%)$ \\
\hline Number of lanes & Two-lane $(63 \%)$ & Four-lane $(49 \%)$ \\
\hline Speed limit (mph) & $51-60(47 \%)$ & $51-60(47 \%)$ \\
\hline Accident location & Non-intersection (67\%) & Non-intersection (58\%) \\
\hline Surface type & Asphalt $(69 \%)$ & Asphalt (61\%) \\
\hline Road special feature & None $(85 \%)$ & None $(85 \%)$ \\
\hline Area information & Rural (84\%) & Rural (86\%) \\
\hline Traffic control & Center/edge lines $(80 \%)$ & Center/edge lines $(72 \%)$ \\
\hline \multicolumn{3}{|l|}{ Contributing factor } \\
\hline Driver factor & Inattention $(53 \%)$ & Inattention $(51 \%)$ \\
\hline Pedestrian factor & Illegal in road $(2 \%)$ & - \\
\hline Environment factor & Rain, mist, or drizzle $(2 \%)$ & Rain, mist, or drizzle $(2 \%)$ \\
\hline Vehicle factor & Tires $(1 \%)$ & Brakes/tires (1\%) \\
\hline
\end{tabular}

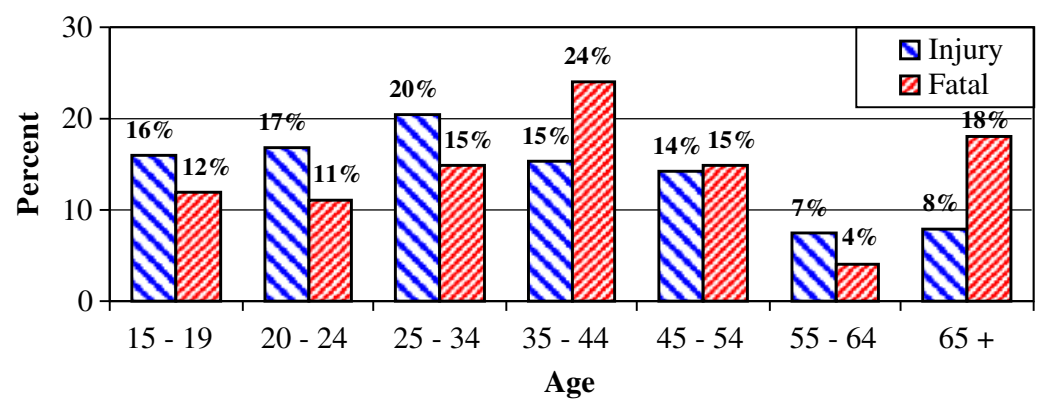

Fig. 1. Fatal and injury accident percent frequencies by age.

caused by the same age group. Senior drivers ( 65 or older) were found to be responsible for a much larger proportion of fatal accidents than for injury accidents. 


\subsection{Time information}

As seen from Fig. 2, daytime non-peak hours (10:00 a.m.-4:00 p.m.) had the highest injury accident frequency and the second highest fatal accident frequency $(42 \%$ and $32 \%$, respectively). A large percentage of the fatal accidents occurred in nighttime between 8:00 p.m. and 6:00 a.m., 19\% more (37\% vs. 18\%) than injury crashes in this time period. chi-square tests indicated that multi-vehicle injury accidents frequently occurred during daytime non-peak hours. When comparing days, the lowest injury accident frequency was observed on Sundays while no significant differences in percentages of fatal accidents were found among days of a week. The majority of both fatal and injury accidents occurred in the busy construction season from April to November.

\subsection{Climatic environment}

The study found that an overwhelming proportion of both the fatal and injury accidents occurred when weather and road surface conditions were favorable. Poor light conditions such as dust, dawn, and dark with or without street lights contributed to a considerably larger proportion of fatal accidents than to injury accidents (47\% vs. 25\%). In particular, $32 \%$ of the fatal accidents occurred in darkness without streetlights, while this unfavorable light condition only contributed to $13 \%$ of the injury accidents. This significant difference indicated that the poor light condition was one of the causes leading to fatal construction zone accidents. The fatal and injury accident frequencies by light conditions are illustrated in Fig. 3.

\subsection{Accident information}

Accident information indicated that before a severe accident occurred, most vehicles at fault were straight following roads. Multi-vehicle accidents were dominant for both fatal $(68 \%)$ and injury $(70 \%)$ accidents in Kansas construction zones. As seen in Fig. 4, among multi-vehicle collisions, head-on was the dominant type for fatal accidents, followed by angle-side impact and rear-end. Rear-end collisions were the dominant injury accident type, followed by angle-side impact collisions and fixed-object collisions. The dominance of rear-end collisions in the injury accidents suggests that relatively high speed combined with following too close was a contributing factor for the injury accidents. In addition, the

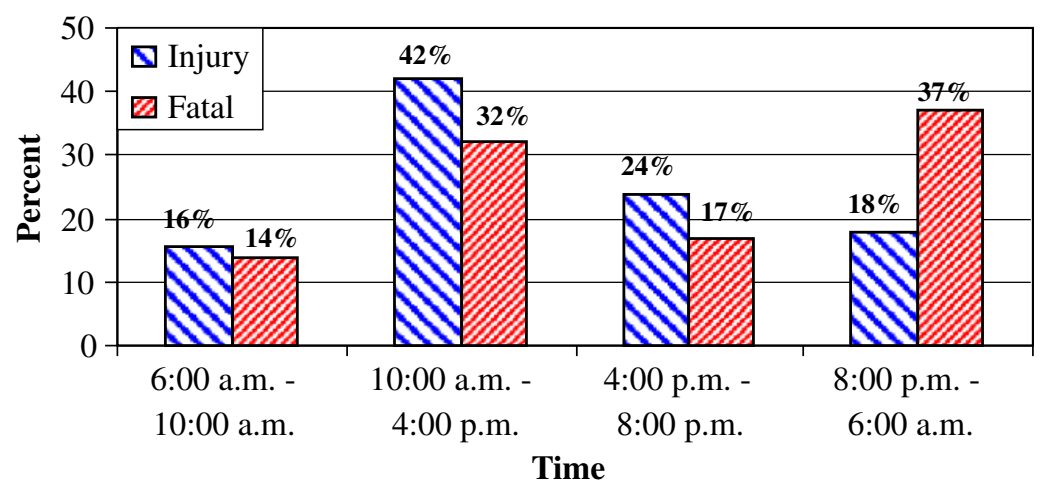

Fig. 2. Fatal and injury accident percent frequencies by accident time. 


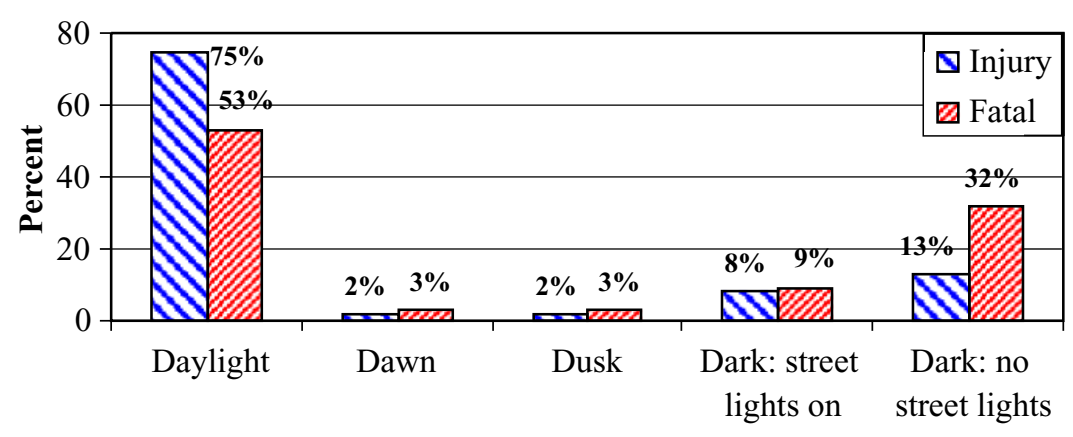

Light Condition

Fig. 3. Fatal and injury accident percent frequencies by light conditions.

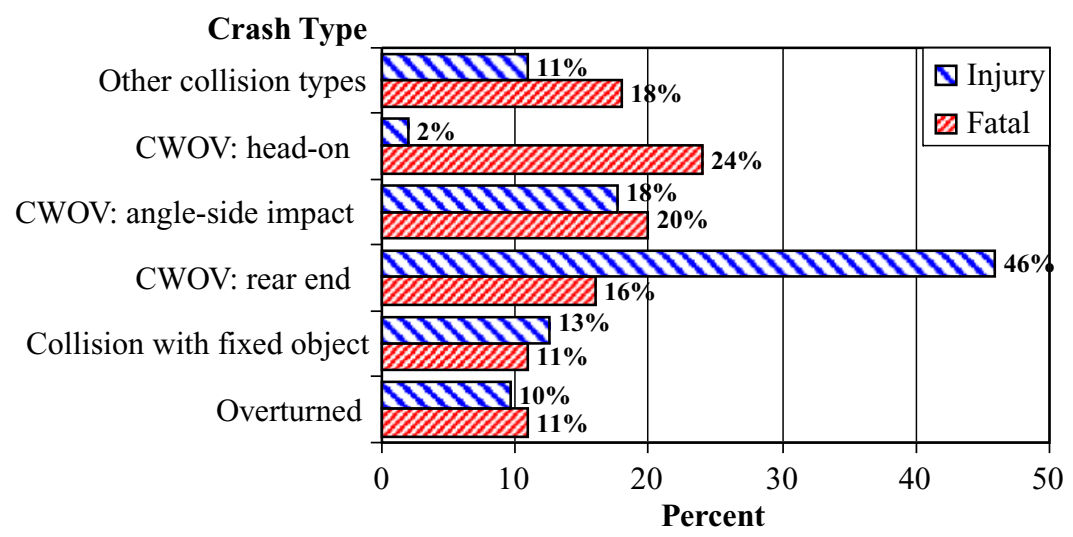

Fig. 4. Fatal and injury accident percent frequencies by accident type (CWOV: collision with other vehicles).

large percentage of head-on collisions in the fatal crashes indicates that there is a need to install median separators in construction zones.

Analyses showed that most ( $82 \%$ ) injury accidents involved only light-duty vehicles. On the contrary, about $40 \%$ of the fatal accidents involved heavy trucks and almost all of these accidents were multi-vehicle accidents. The term "truck" here refers to the heavy vehicle types such as single large truck, truck and trailer, tractor-trailer, and buses. These results imply that truck involvement could increase the severity of construction zone accidents.

\subsection{Road condition}

A dominant proportion of both fatal and injury accidents took place in construction zones on interstate highways and other principal arterials which is shown in Fig. 5. Most of the fatal and injury accidents were in rural areas within $51-70 \mathrm{mph}(82-113 \mathrm{~km} / \mathrm{h})$ speed zones. Statistical tests indicated that almost half of the single-vehicle fatal and injury accidents occurred on interstate highways and one third of the multi-vehicle fatal and injury accidents occurred in intersections or intersection-related areas.

Compared with fatal accidents, injury accidents were more likely to occur on multi-lane highways, especially on four-lane highways. Data analyses showed that $63 \%$ of the construction zone fatal accidents occurred on two-lane highways while $77 \%$ of the injury accidents were on highways with multiple lanes in each direction. Combining the findings discussed earlier that the most common accident type for the injury accidents was rear-end 


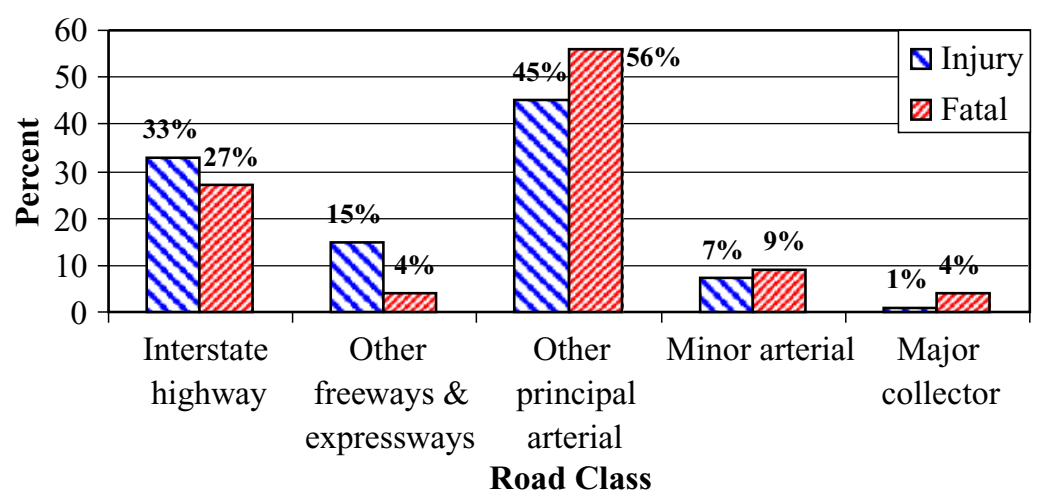

Fig. 5. Fatal and injury accident percent frequencies by road class.

while head-on was the most common for fatal accidents, this difference suggests that injury accidents were more attributed to high traffic volumes than fatal accidents.

The fatal and injury accident distributions over speed limits had practical differences worthy of discussion. As shown in Fig. 6, 51-60 mph $(82-97 \mathrm{~km} / \mathrm{h})$ speed zones had the highest proportion of both fatal and injury accidents. With decreasing speed limits, there was a larger percentage of injury accidents. On the other side, with increasing speed limits, there was a larger percentage of fatal accidents occurred on highways with high speed limits between 61 and $70 \mathrm{mph}(98-113 \mathrm{~km} / \mathrm{h})$. This tendency confirmed that high speeds contributed to the increase of accident severity in the construction zones.

In terms of road characteristics, $66 \%$ of the injury accidents occurred in construction zones on straight and level highway sections and only $34 \%$ of the injury accidents were on highway sections with complicated geometric-alignment features such as grades, curvatures, and hillcrests. Almost half $(49 \%)$ of the fatal accidents, however, were in construction zones on highway sections with complex alignments. In particular, among the complex alignments, straight on grade contributed to the highest proportion of both injury accidents (18\%) and fatal accidents $(25 \%)$. Therefore, the presence of complicated highway alignment features, especially grades, could potentially increase the severity of accidents in the construction zones. Fig. 7 illustrate the accident distributions over road characters.

\subsection{Contributing factor}

Inattentive driving contributed to more than half of both fatal and injury accidents. Followed too closely caused $14 \%$ more injury accidents than fatal accidents $(18 \%$ vs.

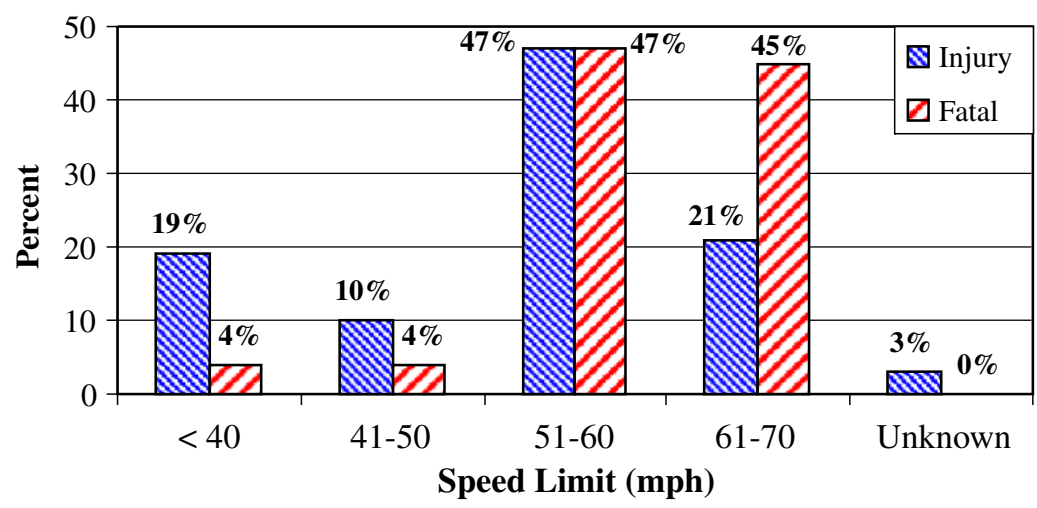

Fig. 6. Fatal and injury accident percent frequencies by speed limit. 


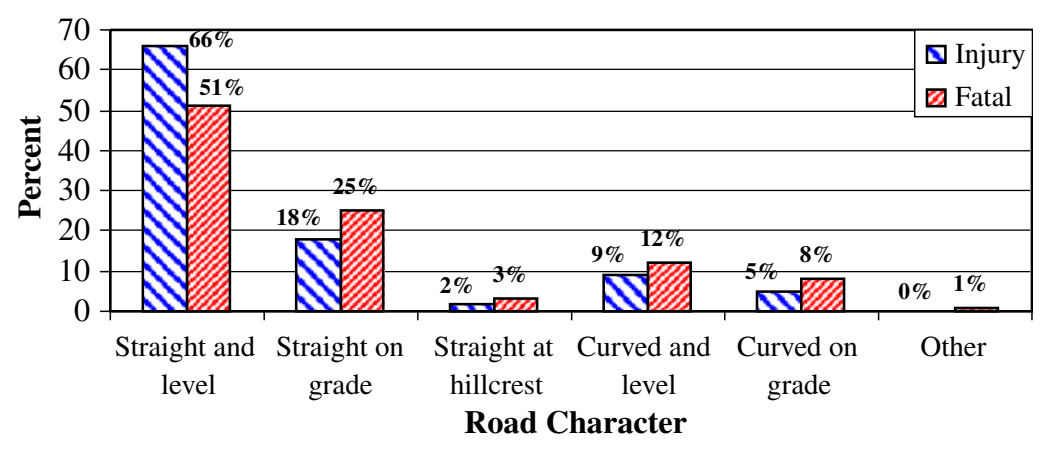

Fig. 7. Fatal and injury accident percent frequencies by road character.

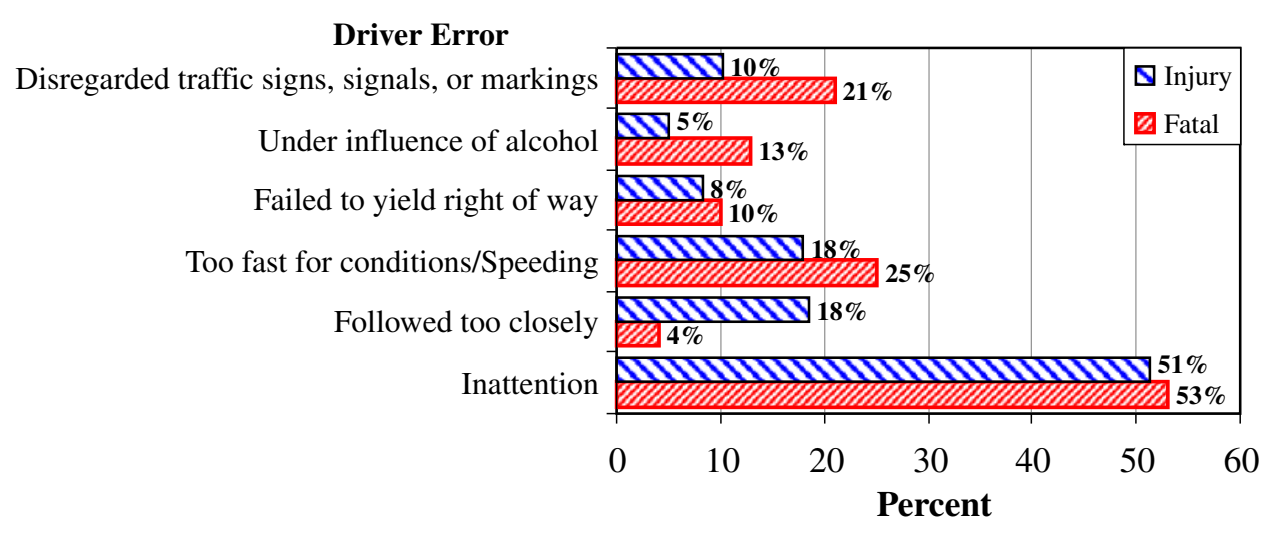

Fig. 8. Fatal and injury accident percent frequencies by driver error.

4\%). On the other hand, some other driver errors such as "disregarded traffic signs, signals, or markings" and "under influence of alcohol" resulted in notably higher percentages of fatal accidents than injury accidents. The accident frequencies by major driver errors are presented in Fig. 8.

\section{Conclusions and recommendations}

\subsection{Conclusions}

The characteristics of fatal and injury accidents in Kansas construction zones were investigated systematically utilizing statistical techniques such as frequency analysis and tests of independence. Significantly different characteristics between the two types of the accidents were further identified in an effort to discover the factors that contributed to the increase of accident severity. The results also provide practical insights to facilitate the development of construction zone traffic control strategies that could not only reduce the number of accidents but also mitigate the accident severity.

The comparison study discovered a variety of differences in characteristics between fatal and injury accidents. Major differences are summarized in Table 3. These characteristic differences were discovered in the aspects including drivers at fault, accident time, accident location, accident type, and causal factors. The researchers found that complicated geometric highway alignments (especially grades), unfavorable light conditions, involvement of heavy vehicles, alcohol impairment, and disregarding traffic control, were 
Table 3

Major characteristic differences between fatal and injury accidents

\begin{tabular}{|c|c|c|}
\hline Category & Fatal accident characteristics & Injury accident characteristics \\
\hline $\begin{array}{l}\text { Drivers at } \\
\text { fault }\end{array}$ & $\begin{array}{l}\text { Drivers between } 35 \text { and } 44 \text { and older than } 64 \\
\text { frequently caused more fatal accidents }\end{array}$ & $\begin{array}{l}\text { Drivers younger than } 35 \text {, especially those between } \\
15 \text { and } 24 \text {, frequently caused injury accidents }\end{array}$ \\
\hline $\begin{array}{l}\text { Accident } \\
\text { time }\end{array}$ & $\begin{array}{l}\text { A much larger proportion occurred during } \\
\text { nighttime }\end{array}$ & $\begin{array}{l}\text { Daytime non-peak hours had the highest accident } \\
\text { frequency }\end{array}$ \\
\hline $\begin{array}{l}\text { Accident } \\
\text { location }\end{array}$ & $\begin{array}{l}\text { Most accidents took place in } 51-60 \mathrm{mph}(82- \\
97 \mathrm{~km} / \mathrm{h}) \text { and } 61-70 \mathrm{mph}(98-113 \mathrm{~km} / \mathrm{h}) \\
\text { speed zones }\end{array}$ & $\begin{array}{l}51-60 \mathrm{mph}(82-97 \mathrm{~km} / \mathrm{h}) \text { speed zones had almost } \\
\text { half of the accidents; the rest were relatively evenly } \\
\text { distributed in other speed zones }\end{array}$ \\
\hline \multirow{2}{*}{$\begin{array}{l}\text { Accident } \\
\text { type }\end{array}$} & Head-on was the dominant type & Rear-end was the dominant type \\
\hline & A large percent of accidents involved trucks & $\begin{array}{l}\text { A majority of accidents involved only light-duty } \\
\text { vehicles }\end{array}$ \\
\hline \multirow[t]{3}{*}{$\begin{array}{l}\text { Causal } \\
\text { factors }\end{array}$} & $\begin{array}{l}\text { Disregarded traffic control, alcohol } \\
\text { impairment, and speeding caused a much } \\
\text { larger proportion }\end{array}$ & Followed too close caused a much higher percent \\
\hline & $\begin{array}{l}\text { Unfavorable light conditions, especially } \\
\text { nighttime darkness, contributed to a larger } \\
\text { proportion }\end{array}$ & $\begin{array}{l}\text { A majority occurred when light conditions were } \\
\text { favorable }\end{array}$ \\
\hline & $\begin{array}{l}\text { Complicated road geometries contributed to } \\
\text { a larger proportion }\end{array}$ & $\begin{array}{l}\text { A majority occurred on straight and level } \\
\text { highways }\end{array}$ \\
\hline
\end{tabular}

potential factors that contributed to the increase of accident severity in construction zones. Comparison results also suggested that the fatal accidents were more related to high speeds while the injury accidents were more related to high traffic volumes.

\subsection{Recommendations}

Improvement of traffic control is the most direct method to reduce highway construction zone accidents. More effective and sufficient construction zone traffic controls should be installed. In particular, there is an urgent need to develop speed control methods that can be strictly enforced in the construction zones. Illumination or highly retroreflective devices should be installed in the construction zones that stay set up at night. Devices such as transverse markings or temporary raised pavement markers in the advance warning areas may be used to alert inattentive travelers of the upcoming construction zones. Installation of median separators is necessary in construction zones to eliminate head-on crashes. Lower speed limits should be considered in construction zones with complex highway geometric alignments. Special traffic control strategies need to be developed to guide trucks passing the construction zones.

Male teenage drivers and drivers younger than 35 years of age frequently caused construction zone injury accidents. Drivers aged 35-44 and older than 64 were the groups with the highest fatal accident rate in Kansas construction zones. Truck drivers also create serious safety problems in construction zones. The authors suggest the launch of special-driver-group-oriented education programs in order to raise awareness on highway construction zone hazards. The fact that a major cause of most accidents was human errors also indicates the urgency for developing effective training programs to educate the traveling public. 
In addition, some sections of the state of Kansas motor vehicle accident report need to be modified to better facilitate construction zone accident investigation. For instance, the traffic control devices listed on the report do not include temporary traffic control devices such as channelizing devices and temporary lighting devices that are commonly used in construction zones. As a result, accident investigators (police) usually either classify those temporary construction zone traffic control devices as "other" or do not record them. Revisions might also be considered for other sections such as pedestrian identification (regular pedestrian or construction worker), and detailed accident locations within construction zones (advance warning area, transition area, activity area, or termination area). Descriptions of the construction zone including the construction work types and construction activities at the accident scene should be also included in the accident reports.

\section{Acknowledgements}

The authors thank Mr. Anthony Alrobaire, Mr. Kurt Miyamoto, and Mr. Rex McCommon from KDOT for their valuable help and advice during the course of this study. Cooperation and assistance from other KDOT staff during the process of accident data collection are also greatly appreciated. Thanks also goes to Dr. Yaozhong Hu for his valuable advice during the course of this study. The financial support that contributed to the success of this research was fully provided by KDOT.

\section{References}

AASHTO, 1987. Summary report on work zone crashes. Standing Committee on Highway Traffic Safety, American Association of State Highway and Transportation Officials, Washington, DC.

Bai, Y., 2002. Improving highway work zone safety. In: Proceedings of the Fall Meeting of American Society of Civil Engineers (Texas section), Waco, Texas, CD-ROM.

Bai, Y., Cao, Q., 2003. Reducing fatalities in highway construction work zones. In: Proceedings of 33rd Annual Meeting of Southeast Decision Sciences Institute, Williamsburg, Virginia, pp. 367-369.

Bai, Y., Li, Y., 2006. Determining major causes of highway work zone accidents in Kansas. Final Report No. KTRAN: KU-05-01, the University of Kansas, Lawrence, Kansas.

Benekohal, R.F., Shim, E., Resende, P.T.V., 1995. Truck drivers' concerns in work zones: travel characteristics and accident experiences. Transportation Research Record 1509, Transportation Research Board, Washington, DC, pp. 55-64.

Chambless, J., Chadiali, A.M., Lindly, J. K, McFadden, J., 2002. Multistate work zone crash characteristics. ITE Journal, Institute of Transportation Engineers, pp. 46-50.

Daniel J., Dixon, K., Jared, D., 2000. Analysis of fatal crashes in Georgia work zones. Transportation Research Record 1715. Transportation Research Board, Washington, DC, pp. 18-23.

FHWA, 2004. Work zone safety facts and statistics. Federal Highway Administration (FHWA). <http:// safety.fhwa.dot.gov/wz/wz_facts.htm>, updated on December 24, 2004.

FHWA, 2006. Highway Statistics 2004, Section III: Driver licensing. Federal Highway Administration (FHWA). $<$ http://www.fhwa.dot.gov/policy/ohim/hs04/dl.htm>, last updated on March 14, 2006.

Graham, J., Paulsen, R., Glennon, J., 1977. Accident and speed studies in construction zones. Report FHWARD-77-80, Federal Highway Administration (FHWA).

Garber, N.J., Woo, T.H., 1990. Accident characteristics at construction and maintenance zones in urban areas. Report No. VTRC 90-R12. Virginia Transportation Research Council.

Garber, N.J., Zhao, M., 2002. Crash characteristics at work zones. Research Report VTRC 02-R12, Virginia Transportation Research Council, Charlottesville, Virginia.

Ha, T., Nemeth, Z.A., 1995. Detailed study of accident experience in construction and maintenance zones. Transportation Research Record 1509, Transportation Research Board, Washington, DC, pp. 38-45. 
Hall, J.W., Lorenz, V.M., 1989. Characteristics of construction zone crashes. Transportation Research Record 1230, Transportation Research Board, Washington, DC, pp. 20-27.

Hargroves, B.T., 1981. Vehicle crashes in highway work zones. In: Journal of Transportation Engineering 107 (TE5). ASCE, pp. 525-539.

Hill, R.W., 2003. Statistical analysis of fatal traffic accident data. Master's Thesis, Texas Tech University.

Li, Y., Bai, Y., 2006. Investigating the characteristics of fatal crashes in the highway construction zones. In: Proceedings of CIB W99 International Conference on Global Unity for Safety and Health in Construction, Beijing China, June 28-30.

Mohan, S.B., Gautam, P., 2002. Cost of highway work zone injuries. In: Practical Periodical on Structural Design and Construction, vol. 7. ASCE (2), pp. 68-73.

Nemeth, Z.A., Migletz, D.J., 1978. Accident characteristics before, during, and after safety upgrading projects on Ohio's rural interstate system. Transportation Research Record 672, Transportation Research Board, Washington, DC, pp. 19-23.

Pal, R., Sinha, K.C., 1996. Analysis of crash rates at interstate work zones in Indiana. Transportation Research Record 1529, Transportation Research Board, Washington, DC pp. 43-53.

Pigman, J.G., Agent, K.R., 1990. Highway crashes in construction and maintenance work zones. Transportation Research Record 1270, Transportation Research Board, Washington, DC, pp. 12-21.

Rouphail, N.M., Yang, Z.S., Frazio, J., 1988. Comparative study of short- and long-term urban freeway work zones. Transportation Research Record 1163, Transportation Research Board, Washington, DC, pp. 4-14.

Schrock, D.S., Ullman, G.L., Cothron, A.S., Kraus, E., Voigt, A.P., 2004. An analysis of fatal work zone crashes in texas. Report FHWA/TX-05/0-4028-1, FHWA, US Department of Transportation.

Sorock, G.S., Rainey, T.A., Lehto, M.R. 1996. Motor vehicle crashes in roadway construction workzones: an analysis using narrative text from insurance claims. Accident Analysis and Prevention, 28(1), pp. 131-138.

Thompson, S.K., 2002. Sampling, second ed. John Willy and Sons Inc, pp. 11-17.

Ullman, G.L., Krammes, R.A., 1990. Analysis of crashes at long-term construction projects in Texas, Report FHWA/TX-90/1108-2, Federal Highway Administration (FHWA).

UT, 2005. Tests of independence using two-way contingency tables in SPSS. $<$ http://www.utexas.edu/cc/docs/ stat58.html\#testing>, the University of Texas at Austin. Accessed on June 12, 2005.

Wang, J., Hughes, W.E., Council, F.M., Paniati, J.E., 1996. Investigation of highway work zone crashes: what we know and what we don't know. Transportation Research Record 1529, Transportation Research Board, Washington, DC, pp. 54-64. 